\title{
The relationship between some demographic characteristics and organizational commitment of nurses working in the Social Security Hospital of Khorramabad
}

Faribah Sepahvand ${ }^{1,2}$, Foorozan Atashzadeh-Shoorideh ${ }^{3}$, Soroor Parvizy ${ }^{4}$, Mansoureh Zagheri Tafreshi $^{5}$

${ }^{1}$ Ph.D. Student of Nursing, Department of Nursing Management, School of Nursing \& Midwifery, Shahid Beheshti University of Medical Sciences, Tehran, Iran

${ }^{2}$ Nursing Manager of Iranian Social Security Organization, Khorramabad, Iran

${ }^{3}$ Ph.D. of Nursing, Associate Professor, Department of Nursing Management, School of Nursing \& Midwifery, Shahid Beheshti University of Medical Sciences, Tehran, Iran

${ }^{4}$ Ph.D. of Nursing, Professor, Department of Pediatric Nursing, School of Nursing and Midwifery, Iran Medical Sciences University, Tehran, Iran

${ }^{5} \mathrm{Ph} . \mathrm{D}$. of Nursing, Associate professor, Department of Nursing Management, School of Nursing and Midwifery, Shahid Beheshti University of Medical Sciences, Tehran, Iran

Type of article: Original

\begin{abstract}
Background: Reduction in organizational commitment of nurses results in deficiency of care services. Some demographic factors affect organizational commitment.

Objective: The present study is intended to determine the organizational commitment of nurses and its relationship with demographic characteristics.

Methods: This study was a descriptive correlation (cross-sectional) study in January and February of 2016 on 126 nurses who held Bachelor of Science (B.Sc.) or Master of Science (M.Sc.) and at least one year of work experience in the Social Security Hospital of Khorramabad, selected using the census method. Data collection tools included a demographic characteristics form and Allen and Meyer questionnaire. Data analysis was performed using SPSS 20. Independent-samples t-test and one-way ANOVA were used to determine the relationship between organizational commitment and demographic characteristics.

Results: The majority of nurses had moderate organizational commitment, the highest score belonging to the continuance commitment $(22.33 \%)$, and the lowest score belonging to the normative commitment $(19.16 \%)$. Also, there was a significant correlation between the continuance commitment and work experience $(\mathrm{p}=0.001)$, the staff posts $(\mathrm{p}=0.01)$ and shifts $(\mathrm{p}=0.04)$.

Conclusion: Considering the moderate level of subjects' organizational commitment in the present study, managers should take necessary measures to increase the attachment and organizational commitment of nurses and provide the ground for improving nursing services.
\end{abstract}

Keywords: Organization, Commitment, Demographic factors, Nurses

\section{Introduction}

Staff organizational commitment is a crucial factor in achieving organizational goals $(1,2)$ and only those organizations that attach importance to their staff and provide appropriate grounds for their activities are able to survive and thus improve the organizational commitment among the nurses $(3,4)$. The organizational commitment definitions have been presented in various sources (5) Management experts define commitment as attitude or orientation toward the organization $(6,7)$. The organizational commitment as an attitude includes a strong desire to stay in the organization, exert extra effort for the organization, and a strong belief in accepting its values and goals

\section{Corresponding author:}

Associate Professor Dr. Foorozan Atashzadeh-Shoorideh, Department of Nursing Management, School of Nursing \& Midwifery, Shahid Beheshti University of Medical Sciences, Tehran, Iran.

Tel: +98.2188655366, Email: f_atashzadeh@sbmu.ac.ir

Received: November 15, 2016, Accepted: February 25, 2017, Published: June 2017

iThenticate screening: February 09, 2017, English editing: March 25, 2017, Quality control: April 24, 2017

(C) 2017 The Authors. This is an open access article under the terms of the Creative Commons Attribution-NonCommercialNoDerivs License, which permits use and distribution in any medium, provided the original work is properly cited, the use is non-commercial and no modifications or adaptations are made. 
(8). The organizational commitment refers to the links between organizations and the staff having different ideas about its components. Meyer and Allen stated that commitment includes affective, continuance and normative dimensions. Affective commitment: refers to staff's affective attachment to be identified with the organizations and engaging in the organization's activities with positive emotions. Continuance commitment: includes a value-based commitment to the organization and the employee is involved in the organization's activities and has high loyalty to the organization. Normative commitment: refers to individuals' feelings based on the need to stay in the organization. Staff with strong normative commitment stay in the organization because they feel so $(4,7,9-12)$. Staff's high organizational commitment leads to the desire to make great efforts in achieving organizational goals, having more job satisfaction, high tendency to stay in the organization, reduced turnover and absenteeism rate, increased staff's mental freshness, improved organization's performance, better manifestation of personal and organizational lofty goals (7), and represents staff's views toward their organization and job (9, 12-16).

In contrast, reduced organizational commitment leads to negative consequences for the individual and the organization (13), such as reduced productivity and individual performance, perceived discrimination in the organization, ignoring needs of the personnel, lack of participation in organizational issues, high absenteeism, delay in the arrival of employees, unwillingness to stay in the organization, turnover, reduced customers' trust, reduced revenue and lack of motivation $(13,17)$. Today, reduced organizational commitment has involved the international community, including health organizations along with other organizations. Nurses' organizational commitment, as the largest human resource ( $40 \%$ to $60 \%)$ in each health organizations, finds special significance because the quality of nursing affects the overall judgment toward the hospital and its performance (13). The most important side effects of reduced organizational commitment among nurses include increased turnover rate, loss of motivation and job satisfaction, and reduced performance level and subsequent "loss of care services and hospital efficiency" and reduction in patient satisfaction (18). Shaw stated that organizational commitment and its effectiveness can affect the manner of service delivery, quality of care, and patient satisfaction (19). Javadi and Jafari stated that managers should seek to create ways to increase the efficiency and quality of services provided to the patients by recognizing the factors affecting the staff's organizational commitment (20). Larber and Savis concluded that many factors affect the organizational commitment (personal, occupational, structural, etc.), and it is very important to identify them and their effects on the organizational commitments (6). In their study, Farahabadi et al. stated the staff's organizational commitment in Isfahan's Emergency Center has a relationship with some demographic factors (21). Abedi, et al. also studied this relationship among physical training teachers (22). Because few similar studies were conducted on nurses and also due to the significance of organizational commitment for giving care services to patients, it seemed imperative to conduct a research in this regard. Thus, the researchers decided to study the relationship between demographic features and nurses' organizational commitment in Social Security Hospital in Khorramabad.

\section{Material and Methods}

\subsection{Design and participants}

This study was a cross-sectional study conducted in January and February of 2016. The research setting included the Social Security Hospital in Khorramabad. The target population included all nurses (126 nurses) working in different wards of the hospital. The census method was used to select nurses. The inclusion criteria were all nurses with B.Sc. or M.Sc. in nursing and at least one year of working experience.

\subsection{Data collection tools}

Two questionnaires were used to collect the data: 1) demographic characteristics questionnaire that included questions about age, gender, marital status, level of education, type of employment, work experience, shift, overtime levels, location of work and the employees' positions; 2) Meyer and Allen's organizational commitment, which has 24 items, measuring the organizational commitment in three dimensions of affective (items 1 to 8 ), continuance (items 9 to 16), and normative commitment (items 17 to 24). These statements were set based on a 5-point Likert scale from strongly disagree to strongly agree. Organizational commitment scores were classified in three levels: low level of organizational commitment (0-33), moderate level of organizational commitment (34-67), and high level of organizational commitment (68-100). To obtain the validity of the three scales of the organizational commitment by correlating each scale to other scales of the questionnaire, Meyer and Allen reported the correlation between the test scores and total scores between $0.60 \%$ to $0.70 \%$ and reliability coefficients of $0.85,0.79$, and 0.73 for affective, continuance, and normative commitments, respectively (23). This questionnaire has been used in numerous dissertations in nursing research in Iran. This instrument was translated into Farsi by Shoorideh et al. (24). The authors reported the content validity index for the whole instrument was 0.87 , affective commitment (0.82), continuance commitment (0.89), and normative commitment (0.75). Also the stability of the instrument was 
estimated 0.93, using the test-retest affective commitment (0.93), continuance commitment (0.89), and normative commitment (0.78) (24). In this study, the internal consistency and Cronbach's alpha were used in order to assess the reliability of the questionnaire. The questionnaires were first given to 20 nurses, and they were analyzed after the completion of the data collection phase. Cronbach's alpha coefficient was calculated $0.89,0.79,0.89$, and 0.87, for the whole instrument, affective, continuance, and normative commitments, respectively. The instrument's stability was also calculated $(\mathrm{r}=0.94)$ for the whole organizational commitment instrument using intra-class correlation coefficient (ICC) within 14 days.

\subsection{Ethical considerations}

This study was approved by the Ethics Committee of Nursing \& Midwifery School of Shahid Beheshti University of Medical Sciences (SBMU2.REC.1394.103). All of the subjects were informed regarding the details of the study, and they signed a written informed consent. Questionnaires were given to all of the nurses in the hospital (126) and were completed in three shifts. All 126 questionnaires were completed and were returned to the researcher.

\subsection{Statistical analyses}

The collected data were analyzed using SPSS 20. In order to achieve specific objectives and answer the research questions, descriptive statistics such as tables and the central and dispersion indices (mean and standard deviation) were used. Also, inferential statistics, including independent-samples t-test and one-way ANOVA were used at a significance level of 0.05 .

\section{Results}

Results of the analysis of demographic questionnaires showed that $48.8 \%$ of nurses aged between 31 and 40 . Female and married individuals accounted for the $94.9 \%$ and $74.4 \%$ of the participants. A total $94.9 \%, 48.7 \%$, and $79.5 \%$ of the nurses had a B.Sc., 10 years of work experience, and rotational shift work, respectively. In addition, $48.7 \%$ of them worked overtime, about 26 to 50 hours. Permanent nurses accounted for $53.8 \%$ of the participants, and $47.5 \%$ of them were employed in public wards; $64.1 \%$ of them were nurses with rotational working shifts and did not have any posts.

Table 1. Level of organizational commitment

\begin{tabular}{|l|l|l|l|}
\hline Row & Commitment & Mean & Standard deviation \\
\hline 1 & Affective Commitment & 21.07 & 0.39 \\
\hline 2 & Continuance commitment & 22.33 & 5.53 \\
\hline 3 & Normative commitment & 19.16 & 7.03 \\
\hline 4 & Organizational commitment (total) & 62.56 & 14.35 \\
\hline
\end{tabular}

Table 2. Correlation between demographic characteristics and organizational commitment

\begin{tabular}{|c|c|c|c|c|}
\hline \multirow[t]{2}{*}{ Demographic } & \multicolumn{4}{|l|}{ Commitment } \\
\hline & $\begin{array}{l}\text { Affective } \\
\text { commitment }\end{array}$ & $\begin{array}{l}\text { Continuance } \\
\text { commitment }\end{array}$ & $\begin{array}{l}\text { Normative } \\
\text { commitment }\end{array}$ & $\begin{array}{l}\text { Organizational } \\
\text { commitment (total) }\end{array}$ \\
\hline Age & 0.13 & 0.19 & 0.12 & 0.18 \\
\hline Gender & 0.27 & 0.11 & 0.12 & 0.13 \\
\hline Marital status & 0.23 & 0.37 & 0.11 & 0.18 \\
\hline $\begin{array}{l}\text { Employment } \\
\text { status }\end{array}$ & 0.12 & 0.23 & 0.09 & 0.11 \\
\hline $\begin{array}{l}\text { Years of } \\
\text { experience }\end{array}$ & 0.42 & $0.001^{*}$ & 0.29 & 0.21 \\
\hline Wards & 0.70 & 0.22 & 0.06 & 0.14 \\
\hline $\begin{array}{l}\text { Level of } \\
\text { education }\end{array}$ & 0.18 & 0.42 & 0.37 & 0.22 \\
\hline $\begin{array}{l}\text { Employees' } \\
\text { positions }\end{array}$ & 0.55 & $0.01 *$ & 0.18 & 0.13 \\
\hline Work shifts & 0.17 & $0.04 *$ & 0.24 & 0.11 \\
\hline Overtime hours & 0.37 & 0.23 & 0.12 & 0.17 \\
\hline
\end{tabular}

Significance level is 0.05 . 
The average organizational commitment of nurses participating in the study was $62.56 \pm 14.35$, which indicates the average level of organizational commitment of nurses. Also, continuance commitment score was higher than those obtained in the affective and normative commitments (Table 1). Results of the independent-samples t-test showed no significant statistical difference among gender, level of education, and the organizational commitment and its dimensions (affective, continuance and normative commitments) (Table 2). One-way ANOVA test results showed no significant statistical difference among age, marital status, employment status, workplace, and overtime work and organizational commitment and its dimensions. The results of one-way ANOVA test showed that there is a statistically significant difference between the years of service $(\mathrm{p}=0.001)$, employees' position $(\mathrm{p}=0.01)$, work shift $(\mathrm{p}=0.04)$ in the continuance commitment, but this difference was not significant in the affective and normative dimensions.

\section{Discussion}

Results of the present study showed a moderate level of organizational commitment of nurses working in the Social Security Hospital of Khorramabad. In a study conducted by Shoorideh et al. (24), nurses also had a moderate level of organizational commitment. However, the results of the study conducted by Kebriaei et al. (25), Larber and Savis (6), Carmen (26), and Siew (27) reflect high commitment levels of nurses. There seems to be some important reasons for the lack of organizational commitment of nurses in the present study and in the majority of health centers in our country, including low number of nurses, increased work pressure, lack of appropriate benefits, and lack of proper working relationship with managers and physicians, which eventually lead to reduced level of organizational commitment. Therefore, providing the necessary conditions to promote this important variable requires serious attention. In the present study, all three dimensions of the organizational commitment were scored at a medium level, but the average score of the continuance commitment was higher than those of the affective and normative commitments. Results of the study conducted by Shoorideh et al. showed that the average continuance commitment of nurses was at the lowest rate possible (24). This means that all of the studied employees had almost the same attitude toward the cost of leaving the government jobs, and leaving the organization is associated with an enormous cost; for this reason, they stay in the organization.

Further, results of this study showed no significant relationship between the age variable and the organizational commitment and its dimensions. Studies conducted by Seyedin et al. (4) and Samadi and Mahdavikhoo (28) also showed the same results. However, studies conducted by Carmen (26), Siew (27) and Jafari et al. (29) showed contrary results. It is now impossible to cite the researchers analyzing the relation between the age and the organizational commitment because, considering the current shortage of nurses in Iran's health centers and the possibility of attracting nurses even after retirement, there is no concern over attracting young and old nurses in health systems, and many medical centers are seeking to employ human resources with higher ages and work experience in order to cut most of the costs associated with education and empowerment and use their useful experience easily. In the present study, there was also no significant relationship between the gender variable and the organizational commitment and its dimensions, which is consistent with results of the study conducted by Jafari et al. (29), Alhawajreh (11), Chen et al. (30). However, results of the study conducted by Seyedin et al. (4) were different from results of the present study. With regard to the results obtained in the present research, it can be stated that, considering today's stressful life and relatively equal gender mix in the workplace and offices and the obligation for vocational activities of both men and women in the society, the question of single-patronage of men and women is not an isolated issue from other factors. Therefore, the organizational commitment of nurses does not differ by gender, and certain other factors affect it. In the present study, there was also no significant relationship between the marital status variable and the organizational commitment and its dimensions. Nartegun and Menep also achieved similar results (31), but results of the study conducted by Salami showed contrary results (32). The reason for obtaining such a result in the present study may be due to the relation of nurses' commitment in both single and married groups with other issues in the organization other than gender. Results of the present study showed that there was no statistically significant relationship between nurses' employment status and their organizational commitment and its dimensions. Results of the present study were consistent with the results obtained in Khalili's study (33).

All nurses working in the Social Security Organization are employed by the organization first on the temporary basis, then as probation and permanent employees, so they have confidence in their job security and know that they will be working for a long time. Therefore, their employment status will have no effect on their organizational commitment. There was no significant relationship between the hospital ward variable and the organizational commitment and its dimensions in the present study. Results of the study conducted by Alhawajreh (11) were 
consistent with results of the current study. Results obtained in the present study may suggest that hospital ward variables cannot have much effect on the organizational commitment of nurses. Results of the present study suggest no difference in organizational commitment between nurses with B.Sc. and M.Sc. degrees. Studies conducted by Larber and savis (6), Seyedin et al. (4), and Samadi and Mahdavikhoo (28) also obtained similar results. Nursing managers of this hospital must define new roles for nurses based on their scientific progress and attempt to attract and retain the personnel with higher education and consider additional facilities for them. There was also no significant relationship between the variable of overtime hours and the organizational commitment and its dimensions, which is consistent with the results obtained by Shoorideh et al. (10). In this study, the organizational commitment of nurses does not differ by overtime, and certain other factors affect it. In the present study, there was a positive correlation among work experience, staff positions, and work shifts with organizational commitment in its continuance commitment dimension. Carmen (26), Siew (27), Zeineldin and AbdelRahman (7), Nartegun, and Menep (31) also found similar results. However, the study conducted by Alhawajreh (11) showed contrary results. It seems that the high commitment level of employees with high work experience in the present study is due to their prolonged exposure to the work environment as well as the impossibility of their separation from their job and finding a job in other work environment. Results of the present study indicate a significant relationship between the employees' positions and their organizational commitment in the continuance dimension, which is consistent with the results obtained by Jeong (34) and Estrada (35). Based on the results of this study, it can be stated that the managerial role among supervisors, lack of rotational work shifts among them, and having clarity and discipline in the working and living conditions give them a positive attitude and better feeling toward the working environment; therefore, they will be more committed to the organization than other nurses. There was also a significant statistical relationship between work shifts and the organization commitment in the continuance dimension. As explained in terms of staff positions, attending the evening and night shifts and on holidays and problems related to the rotational work shifts affected nurses' attitudes toward the hospital and the nursing profession.

The current study had some limitations; one of the most important being that the population studied was limited to the wards of one hospital. In addition, the participants in this study included nurses with B.Sc. and M.Sc. in nursing; thus, the extracted results on the organizational commitment are not applicable to other nursing ranks at the hospital. Majority of the samples in this study were females, and certainly these results should be cautiously generalized to the whole community of nurses of both genders.

\section{Conclusions}

In summary, results of the present study show a moderate level of organizational commitment in nurses and also a positive and significant correlation between continuance organizational commitment and years of experience, staff's positions and work shifts. Such results indicate that managers of nursing should identify related factors and promote the level of organizational commitment in nurses. Some other studies are suggested to be conducted on organizational commitment in a larger population of nurses and managers need to study other factors that affect the organizational commitment of nurses.

\section{Acknowledgments:}

The present paper was derived from a doctoral thesis approved by the Research Committee of Shahid Beheshti University of Medical Sciences in Tehran (code no=6682). The researchers would like to thank Nursing and Midwifery Research Council, Vice Chancellor for Research of Shahid Beheshti University of Medical Sciences, and also the nurses who participated in the research.

\section{Conflict of Interest:}

There is no conflict of interest to be declared.

\section{Authors' contributions:}

All authors contributed to this project and article equally. All authors read and approved the final manuscript.

\section{References:}

1) Atak M. A research on the relation between organization commitment and learning orgazization. African Journal of Buisness Management. 2011; 5(14): 612-6.

2) Karanja WG, Gachunga H, Kalio AM. Effect of Distributive Justice on organizations Commitment of public secondray school teacher in Kenya. International Journal of Science and Research. 2014; 3(7): 1791 6. 
3) Shim M. Factors influencing child welfare employees turnover: Focusing on organizational culture and climate. Child youth serves Rev. 2010; 32(6): 847-56. doi: 10.1016/j.childyouth.2010.02.004.

4) Seyedin H, Zaboli R, Malmoon Z, Azami S. The relationship between ethical values and organizational commitment of staff in public and non-public hospitals. Iranian Journal of Health Sciences. 2013; 1(1): 1-7. doi: 10.18869/acadpub.jhs.1.1.1.

5) Krestaniti E, Prezerakos P. Organizational commitment of the nursing personnel in a Greek national health system hospital. International Journal of Caring Sciences. 2014; 7(1): 252-7.

6) Larber M, Savis SB. Factors affecting nurses organizational commitment. Obzornik zdravstvene Nege. 2014; 48(4): 294-301. doi: 10.14528/snr.2014.48.4.34.

7) Zeineldin KY, Abdel Rahman MR. The relationship between nurses perceived pay equity and organizational commitment. life Sience Journal. 2013; 10(2): 889-96.

8) Nagele C, Neuen Schwander MP. Adjustment processes and fit perceptions as predictors of organizational commitment and its consequences in public hospitals and occupational commitment of young workers. Journal of Vocational Behavior. 2014; 85: 385-93. doi: 10.1016/j.jvb.2014.08.011.

9) Yang FH, Chang CC. Emotional labour, job satisfaction and organizational commitment amongst clinical nurses: A questionnaire survey. Int J Nurs Stud. 2008; 45(6): 879-87. doi: 10.1016/j.ijnurstu.2007.02.001. PMID: 17391673.

10) Shoorideh FA, Nabizadeh Z, Khazaei N, Alavi-Majd H. The study of correlation between organizational commitment and job satisfaction of nurses working in selected hospitals of Isfahan University of Medical Sciences. Scientific Journal of Pure and Applied Sciences. 2014; 3(8): 748-55.

11) Alhawajreh MK. Exploring the relationship between occupational stress and organizaitional commitment among nurses in selected Jordanian hospital. Dirasat: Administrative sciences. 2013; 40(1): 127-43. doi: $10.12816 / 0000638$.

12) Ahadi S, Suandi T. Structural empowerment and organizational commitment: The mediating role of psychological empowement in Malaysian Research Universities. Journal Asian Dev Stud. 2014; 3(1): 4465.

13) Chen SY, Wu W, Chang CS, Lin CT, Kung JY, Weng HC, et al. Organizational justice, trust and identification and their effects on organizational commitment in hospital nursing staff. BMC Health Serv Res. 2015; 15: 1-17. doi: 10.1186/s12913-015-1016-8. PMID: 26347451, PMCID: PMC4562203.

14) Aubé C, Rousseau V, Morin E. Perceived organizational support and organizational commitment: The moderating effect of locus control and work autonomy. Journal of Managerial Psychology. 2007; 22 (5): 479-95. doi: 10.1108/02683940710757209.

15) Lee J, Peccei R. Perceived organizational support and affective commitment: The mediating role of organization-based self-esteem in the context of job insecurity. Journal of Organizational Behavior. 2007; 28(6): 661-85. doi: 10.1002/job.431.

16) Schalk R. The influence of organizational commitment and health on sickness absenteeism: a longitudinal study. J Nurs Manag. 2011; 19(5): 596-600. doi: 10.1111/j.1365-2834.2010.01170.x. PMID: 21749533.

17) Hajipourabayi N, Hajipourabayi E, Afsharipour G. A study on correlation of emotional intelligence to leadership styles of nursing managers and nurses organizational commitment in hospitals of Kerman, Iran. International Journal of Scientific Management and Development. 2014; 2(12): 676-80.

18) Bagraim JJ. Commitment and the emigration intentions South Affrican professional nurses. Health SA Gesondheid. 2013; 18(1): 1-7. doi: 10.4102/hsag.v18i1.512.

19) Liou SR. An analysis of the concept of organizational commitment. Nursing Forum. 2008; 43(3): 116-25. doi: 10.1111/j.1744-6198.2008.00103.x. PMID: 18715344.

20) Javadi M, Jafari M. Relationship between orginazational commitment and efficiency of employees working in hospitals of Isfahan university. Iranian Journal of Health Information Management. 2013; 10(7): 104450.

21) Farahabadi ME, Fatahi M, Arteng M, Hassanzadeh A. The relationship between organizational commitment in Isfahan's Emergency Center and demographic factors. Journal of Rescue Corps. 2012; 4(4): 29-38.

22) Abedi E, Razavi MH, Farzan F. Survey and comparison of teachers organizational commitment. Journal of Exercise Management. 2013; 9(17): 143-59.

23) Nazari K, Akamaliah Z, Ramli B. The level of organizational commitment among lectures in technical and vocational colleges in Iran. Journal of Social Sciences \& Humanities. 2012; 20(5): 21 - 40.

24) Atashzadeh Shoorideh F, Nabizadeh Z, Khazaei N, Alavi-Majd H. Correlation between nursing managers' delegation and nurses' organizational commitment from the viewpoint of nurses working in teaching 
hospitals of Isfahan University of medical sciences. Scientific Journal of Pure and Applied Sciences. 2014; 3(8): 735-40.

25) Kebriaei A, Rakhshaninejad M, Mohseni M. Influence of Psychological Empowerment on Organizational Commitment among Medical Employees in a Hospital Setting. Bangladesh Med Res Counc Bull. 2014; 40(3): 107-12. doi: 10.3329/bmrcb.v40i3.25232. PMID: 26402975.

26) Carman M. Organizational commitment among licensed practical nurses: exploring associations with empowerment, conflict and trust. J Conflict and Trust. 2011.

27) Siew PA, Chitpakdee BB, Chontawan RB. Factors predicting organizational commitment among nurses in State Hospitals, Malaysia. International Islamic University of Malaysia. 2011; 10(2): 21-8.

28) Samadi A, Mahdavikhou R. Impacts of managerial ethics en organizational commitment: Case of employees of Hamedan Tax Offairs head office. Tax Journal New Series. 2009; 174(52): 45-71.

29) Jafari S, Afshin T, Jafari K, Barzegar M. Evaluation of organizational commitment among nurses in Intensive Care Units. Journal of Nursing and Midwifery Sciences. 2015; 2(3): 38-43.

30) Chen G, Bilese PD. The role of different levels of leadership in predicting self and collective efficacy evidence for discontinuity. J Appl Psychol. 2002; 87(3): 549-56. PMID: 12090612.

31) Nartgun S, Menep I. The analysis of perception levels of elementary school teachers with regard to organizational commitment. International Journal of Human Sciences. 2010; 7(1): 122-31.

32) Salami SO. Demographic and psychological factors predicting organizational commitment among industrial workers. The Anthropologist. 2008; 10(1): 31-8.

33) Khalili A, Asmavi A. Appraising the impact of gender differences on organizational commitment: Empirical evidence from a private SME in Iran. International Journal of Business and Management. 2012; 7(5): 100-10. doi: 10.5539/ijbm.v7n5p100.

34) Jeong SH, Lee T, Kim IS, Lee MH, Kim MJ. The effect of nurses' use of the principles of learning organization on organizational effectiveness. J Adv Nurse. 2007; 58(1): 53-62. doi: 10.1111/j.13652648.2006.04206.x. PMID: 17394616.

35) Estrada N. Exploring perceptions of a learning organization by RNs and relationship to EBP beliefs and implementation in the acute care setting. Worldviews Evid Based Nurs. 2009; 6(4): 200-9. doi: 10.1111/j.1741-6787.2009.00161.x. PMID: 19686224. 